\title{
Psychometric Analysis of the Bengali Clinical Chronic Obstructive Pulmonary Disease Questionnaire
}

\author{
Aniruddha Banerjee, Laijun Nahar'1, Showket Ahmad Bhat, Ashutosha Kumar, Rachna Goenka², Pralay Sharma ${ }^{3}$, Swapan Paul ${ }^{1}$, Abhijit Chattopadhyay ${ }^{1}$, \\ Sk. Swaif Ali ${ }^{4}$, James Michael ${ }^{5}$, Munmun Koley ${ }^{6}$, Subhranil Saha ${ }^{7}$ \\ Departments of Case Taking and Repertory, ${ }^{1}$ Homoeopathic Materia Medica, ${ }^{2}$ Homoeopathic Pharmacy, ${ }^{3}$ Deputy Medical Superintendent in-Charge and ${ }^{5}$ Organon \\ of Medicine and Homoeopathic Philosophy, National Institute of Homoeopathy, Kolkata, ${ }^{4}$ Intern, Mahesh Bhattacharya Homoeopathic Medical College and Hospital, \\ ${ }^{6}$ Independent Researcher, Baidyabati, Hooghly, Independent Researcher, Shibpur, Howrah, West Bengal, India
}

\section{Abstract}

Background: The Clinical Chronic Obstructive Pulmonary Disease Questionnaire Bengali version (CCQ-B) is a prevalidated, patient-administered, 10-item questionnaire assessing symptom severity (SS) and quality of life in adults suffering from chronic obstructive pulmonary diseases (COPDs). To date, no validated Bengali version of the questionnaire is available. We aimed to translate it into Bengali and examine its psychometric properties. Methods: The CCQ-B was produced by standardized forward-backward translations. A cross-sectional study was conducted to gather responses by consecutive sampling. Reliability was examined using internal consistency $(n=110)$ and test-retest reliability $(n=30)$ analyses, concurrent validity by comparing with COPD Assessment Test questionnaire scores, while construct validity by exploratory principal component analysis (varimax rotation; $n=110)$. Subsequently, confirmatory factor analysis $(\mathrm{CFA} ; n=110)$ was performed to verify the model fit of the a priori identified scales. Results: The internal consistency (Cronbach's $\alpha$ ) for overall CCQ-B was 0.746, indicating acceptable reliability. Satisfactory values of test-retest reliability and concurrent validity were found. On factor analyses, all the items loaded above the prespecified value of 0.3. Varimax rotation identified three components (SS, health and social life, and depression and limitation of activities), explaining $58.2 \%$ of variation. The Kaiser-Meyer-Olkin was 0.734 and Bartlett's test of sphericity was also significant. Goodness-of-fit of the three-component model in CFA was mediocre, but acceptable. Conclusion: The CCQ-B, consisting of 10 items and framed within three components, is a valid and reliable questionnaire but measured different dimensions from the English version.

Keywords: Clinical chronic obstructive pulmonary diseases questionnaire, confirmatory factor analysis, principal component analysis, reliability, validity

\section{INTRODUCTION}

In industrialized and developing countries, chronic obstructive pulmonary disease (COPD) has emerged as one of the leading causes of morbidity and mortality. Health-related quality of life (HRQoL) is an important outcome measure in COPD and increasingly being used to measure the symptom burden and to steer treatment. ${ }^{[1]}$ The Clinical COPD Questionnaire (CCQ) is a 10 -item (scored between 0 and 6), self-administered, HRQoL questionnaire, consisting of three domains (symptoms, functional, and mental), taking $<2$ min to complete, and having good psychometric properties. ${ }^{[2]}$ Its conciseness and ease make it suitable for routine use in clinical practice. The scores of the 10 individual items are summed up to erect the total score and divided by 10 , thus giving a total score between 0 and 6 with higher scores signifying worse HRQoL. It has

\begin{tabular}{|l|l|}
\hline \multicolumn{2}{|c|}{ Access this article online } \\
\hline Quick Response Code: & Website: \\
\hline & www.ijrconline.org \\
\cline { 2 - 2 } & \\
\hline
\end{tabular}

three components - (1) symptoms (items 1, 2, 5, and 6); (2) functional state (items 7, 8, 9, and 10); and (3) mental state (items 3 and 4).

Although COPD Assessment Test (CAT) questionnaire remains the most frequently used questionnaire in COPD studies, there are some circumlocutory indications that the CCQ may have some additional advantages. Patients need lesser assistance to complete the CCQ than CAT. ${ }^{[3]}$ Similarly, in a study evaluating

Address for correspondence: Dr. Aniruddha Banerjee, Department of Case Taking and Repertory, National Institute of Homoeopathy, Block GE, Sector III, Salt Lake, Kolkata - 700 106, West Bengal, India.

E-mail: draniruddhabanerjee@gmail.com

This is an open access journal, and articles are distributed under the terms of the Creative Commons Attribution-NonCommercial-ShareAlike 4.0 License, which allows others to remix, tweak, and build upon the work non-commercially, as long as appropriate credit is given and the new creations are licensed under the identical terms.

For reprints contact: reprints@medknow.com

How to cite this article: Banerjee A, Nahar L, Bhat SA, Kumar A, Goenka R, Sharma P, et al. Psychometric analysis of the Bengali clinical chronic obstructive pulmonary disease questionnaire. Indian J Respir Care 2020;9:40-6.

Received: $12-05-2019$ Accepted: $15-07-2019$
Revised: $14-05-2019$ Published: 08-01-2020 
Banerjee, et al:: Validation of Bengali clinical COPD questionnaire

the psychometric properties of the CCQ, CAT, and St. George's respiratory questionnaire, $>60 \%$ of patients favored CCQ over others for assessing health status of patients suffering from COPD. ${ }^{[4]}$ In addition, in another study, CCQ revealed better responsiveness than $\mathrm{CAT}^{[5]}$ In another review, $\mathrm{CCQ}$ was identified as the most suitable questionnaire in primary care. ${ }^{[6]}$

As no valid Bengali version of the CCQ was available, we aimed to develop a Bengali version of the questionnaire through standardized forward-backward translation and thereafter evaluate whether the CCQ Bengali version (CCQ-B) is a psychometrically sound tool to measure the construct and to examine its cross-cultural adaptation considering linguistic equivalence.

\section{Methods}

\section{Study design}

This noninterventional, cross-sectional, validation study was multifaceted; it consisted of standardized translation procedures, face validation by pilot testing, and field testing and psychometric assessment of the CCQ-B.

\section{Study setting}

It was conducted at National Institute of Homoeopathy, Kolkata, under the Ministry of AYUSH, Government of India. Institutional Ethics Committee approved the protocol before initiation (Ref. No. 5-023/NIH/PG/Ethical Comm. 2009/Vol. III/1964 [A/S]; dated March 27, 2017).

\section{Questionnaire translation stages}

1. Forward translation: An expert committee was constructed, consisting of pulmonologists, linguistic experts, and research methodologists. First, two Bengali speakers, one pulmonologist and one linguistic expert, translated the English version of CCQ into Bengali $\left(\mathrm{T}_{1}\right.$ and $\left.\mathrm{T}_{2}\right)$

2. Synthesis of $\mathrm{T}_{1,2}$ : The two translators then agreed upon a consensus version of the translation $\left(\mathrm{T}_{1,2}\right)$. Then, the expert committee verified the version

3. Back translation: Two English language translators $\left(\mathrm{BT}_{1}\right.$ and $\mathrm{BT}_{2}$; one pulmonologist and one linguistic expert), blinded to the original English version, translated $\mathrm{T}_{1,2}$ back into English independently

4. Committee review: All the translations $\left(\mathrm{T}_{1}\right.$ and $\mathrm{T}_{2}, \mathrm{~T}_{1,2}$, and $\mathrm{B}_{1}$ and $\mathrm{B}_{2}$ ) were reviewed by the committee and a written report was prepared comparing the back-translations with the forward translations. Based on these, the prefinal version was developed

5. Face validation: The prefinal version of the questionnaire was tested on randomly chosen ten patients visiting outpatient clinics of the hospital for the purpose of testing contextual clarity, layout, language transparency, ease of understanding the content and use, comprehensibility of the instructions, and response scales. Difficulties, if any, were noted. A written report was prepared by the interviewers, including detected insufficiencies and recommended changes, and was then submitted back to the committee

6. Committee appraisal: The final version of the CCQ-B was developed by the committee based on the inputs from face validity (supplementary file). The different translation stages and the complete study flow are presented in Figure 1.

\section{Field testing and validation}

During development of the original English version, content validity of the CCQ questionnaire was already evaluated, and we refrained from repeating so.

\section{Inclusion criteria}

Patients aged 18-65 years and with mild-to-severe form of $\mathrm{COPD}^{[7]}$ (ICD-10 code J44.9): mild forced expiratory volume-1 $\mathrm{s}\left(\mathrm{FEV}_{1}\right) \geq 80 \%$ predicted, $\mathrm{FEV}_{1} /$ forced vital capacity (FVC) $<0.7$, moderate $\mathrm{FEV}_{1} 50 \%-79 \%$ predicted, $\mathrm{FEV}_{1} / \mathrm{FVC}<0.7$, and severe $\mathrm{FEV}_{1} 30 \%-49 \%$ predicted, $\mathrm{FEV}_{1} / \mathrm{FVC}<0.7$, ability to read Bengali, and written consent to participate were included. Patients undergoing any therapy for COPD were also included after a washout period of 15 days.

\section{Exclusion criteria}

Patients with very severe COPD, $\mathrm{FEV}_{1} / \mathrm{FVC}<0.7$, and $\mathrm{FEV}_{1}<30 \%$ predicted or $<50 \%$ predicted in addition with chronic respiratory failure, psychiatric diseases, pregnancy and lactation, cases suffering from uncontrolled systemic illness or life-threatening infections or any vital organ failure, and substance abuse and/or dependence were excluded.

Of 127 eligible patients approached, 110 (response rate $86.7 \%$ ) returned the questionnaire and these responses were subjected to exploratory factor analysis (EFA) and 110 further responses (response rate 93.2\%) were subjected to confirmatory factor analysis (CFA).

\section{Sample size}

Recommendations for adequate sample size to conduct factor analysis are between 50 and 250, with most authors recommending at least 100 subjects. ${ }^{[8]}$ Subject-to-item ratio (5:1 or 10:1) was used to calculate the sample size based on Gorsuch's formula, thus indicating a sample size of 50-100. ${ }^{[9]}$ By keeping provision for assumed $10 \%$ missing data, the sample size was enhanced to 110 participants.

\section{Sampling}

Patients suffering from COPD who attended the outpatients of the hospital on the days of data collection were approached by consecutive sampling and were invited to participate in the study.

\section{Data collection}

Before obtaining responses on the CCQ-B, all the participants were provided with patient information sheets in local vernacular Bengali and written informed consents were obtained. Patients' privacy was maintained by concealing all the identifiable information. Another section in the questionnaire sought information regarding patients' sociodemographic 
Banerjee, et al:: Validation of Bengali clinical COPD questionnaire

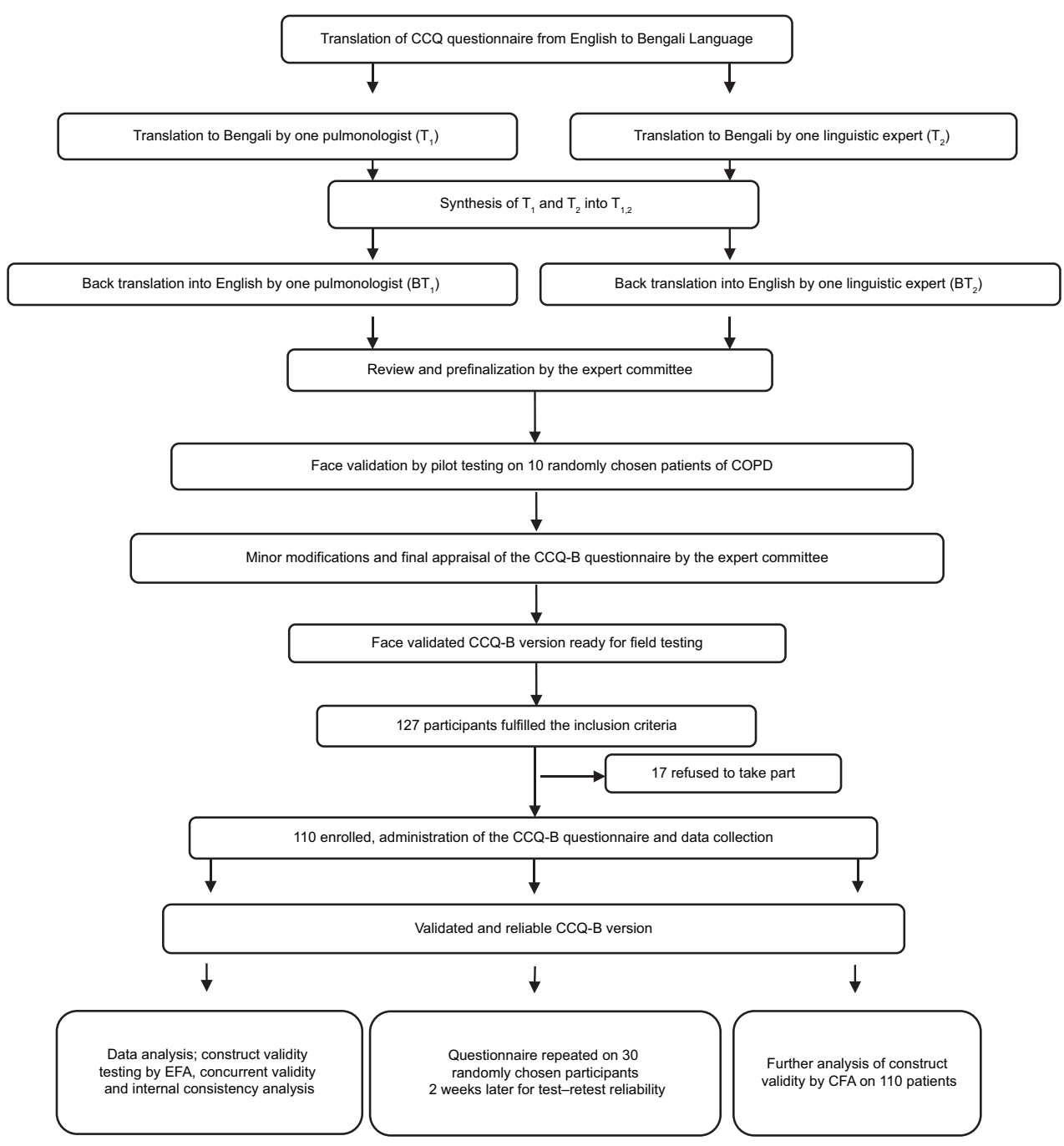

Figure 1: Study flow

features. The filled-in CCQ-B questionnaires were put inside envelops and sealed at the study site. Thirty randomly chosen participants were selected for retest visits at approximately 2-3 weeks' interval to fill the same questionnaire again. All the data were extracted in a specially designed Microsoft Excel spreadsheet and that was analyzed statistically.

\section{Statistical analysis}

It was conducted using IBM ${ }^{\circledR}$ Statistical Package for the Social Sciences (SPSS) ${ }^{\circledR}$ software, version 20.0 and SPSS Amos ${ }^{\circledR}$ version 20.0 (IBM Corp., Armonk, NY, USA). First, adequacy of sample was checked using Kaiser-Meyer-Olkin (KMO) value and data appropriateness for principal component analysis (PCA) was checked using Bartlett's test of sphericity. The KMO value of 0.50 and above ${ }^{[10]}$ with significant Bartlett's test of sphericity $(P<0.05)$ was considered appropriate for factor analysis. Then, EFA using PCA with varimax rotation (eigenvalue $>1$ ) was conducted to examine the CCQ-B unidimensionality of the construct. Only factors with loadings of 0.30 and above were retained. Weak loadings, that is, failure to load $>0.29$ on any component and general loadings of 0.30 on more than one component would lead to exclusion of the items from the matrix. Next, CCQ-B reliability was evaluated by analyses of internal inconsistency and test-retest reliability. High internal consistencies were denoted by Cronbach's alpha of $0.5-0.7^{[11]}$ and average item-total correlation in a moderate range of $0.3-0.9$. Alpha value of 0.9 and above was considered as excellent, while no meaningful construct was indicated by a correlation near $0{ }^{[12]}$ Intraclass correlation coefficient (ICC) values above 0.7 indicated that CCQ-B was stable over time, 0.4-0.7 indicated fair reliability, while poor reliability was demonstrated by values $<0.4$. ${ }^{[13]}$ Paired $t$-test was used on randomly chosen 30 patients' responses to evaluate whether change in scores on the CCQ-B between the test-retest evaluations were statistically significant. Correlation statistics was used to assess the interitem correlations between domains (item discriminant validity) and the overall CCQ-B (internal item convergence). The instrument was considered to be internally consistent if the correlation value was found to be 0.4 or higher. Concurrent validity was examined using Pearson's $r$ statistics comparing the total CCQ-B scores with simultaneously measured CAT scores $(n=110)$. Correlation coefficients of 0.10 were considered being small, 
0.30 as moderate, and 0.50 as large. ${ }^{[14]}$ Finally, a CFA model was developed to verify the goodness-of-fit of the a priori detected scales as suggested by EFA. The goodness-of-fit of the CFA models was evaluated utilizing the following multiple fit indices: comparative fit index (CFI), normed fit index (NFI), Tucker Lewis index (TLI), root mean square error of approximation (RMSEA), standardized root mean square residual (SRMR), Bayesian information criterion (BIC), and Hoelter index. The recommendations for cutoff values indicating a good model fit are CFI/TLI $\geq 0.95$, RMSEA $\leq 0.6$, and $\mathrm{SRMR} \leq 0.8 \cdot{ }^{[15,16]}$ Statistical tests were two-tailed and were conducted with $\alpha$ fixed at 0.05 .

\section{RESULTS}

\section{Descriptive statistics}

These were presented in terms of means, standard deviations, medians, interquartile ranges, skewness, and kurtosis of each individual item. The details are presented in Table 1.

\section{Exploratory factor analysis}

The average communalities after extraction was 0.582 , that is above the preferred cut-off of 0.5 , thus ensuring adequacy

\begin{tabular}{|c|c|c|c|c|}
\hline Items & Mean (SD) & Median (IQR) & Skewness & Kurtosis \\
\hline 1 & $2.8(1.6)$ & $3.0(2.0,4.0)$ & 0.184 & -0.598 \\
\hline 2 & $4.5(1.4)$ & $5.0(4.0,6.0)$ & -1.183 & 1.451 \\
\hline 3 & $4.3(1.6)$ & $5.0(3.0,5.0)$ & -0.990 & 0.354 \\
\hline 4 & $3.2(1.4)$ & $3.0(2.0,4.0)$ & -0.007 & -0.211 \\
\hline 5 & $3.7(1.4)$ & $4.0(3.0,5.0)$ & -0.323 & -0.098 \\
\hline 6 & $3.3(1.8)$ & $3.0(2.0,5.0)$ & 0.131 & -1.073 \\
\hline 7 & $4.4(1.5)$ & $5.0(3.8,6.0)$ & -1.129 & 0.907 \\
\hline 8 & $3.1(1.6)$ & $3.0(2.0,4.0)$ & -0.333 & -0.338 \\
\hline 9 & $1.7(1.5)$ & $2.0(0.0,3.0)$ & 0.660 & 0.087 \\
\hline 10 & $1.4(1.3)$ & $1.0(0.0,2.0)$ & 1.129 & 1.006 \\
\hline
\end{tabular}

SD: Standard deviation, IQR: Interquartile range of sample size of 110 for running PCA. Sample was adequate as evidenced by the $\mathrm{KMO}=0.734$ (Chi-square: 252.061, $P<0.001$ ), much greater than the minimum Kaiser criterion of 0.5. A significant Bartlett's test of sphericity (degrees of freedom $[\mathrm{df}]=45, P<0.001$ ) also signified that the $R$-matrix was not an identity matrix. We performed extraction using principal component method for determining how many factors best explained the observed covariation matrix within the data set. The Scree plot revealed high eigenvalue for the first three components, and thereafter, the curve began to tail off gradually before the final plateau was reached [Figure 2]. The factor component matrix also supported the Scree plot by representing information from initial unrotated solution and extracting three components explaining $58.2 \%$ of the total variance [Table 2]. Each of the components with their respective eigenvalues and percentage of total variances explained are presented in Table 2. The values were weights that related the item (or variable) to the respective factor. Display of coefficients was sorted by size. Factor loadings were similar to regression weights (or slopes) and represented the strength of the association between the variables and the factors. Next, the correlation matrix was searched for values $>0.9$ to identify multicolinearity and

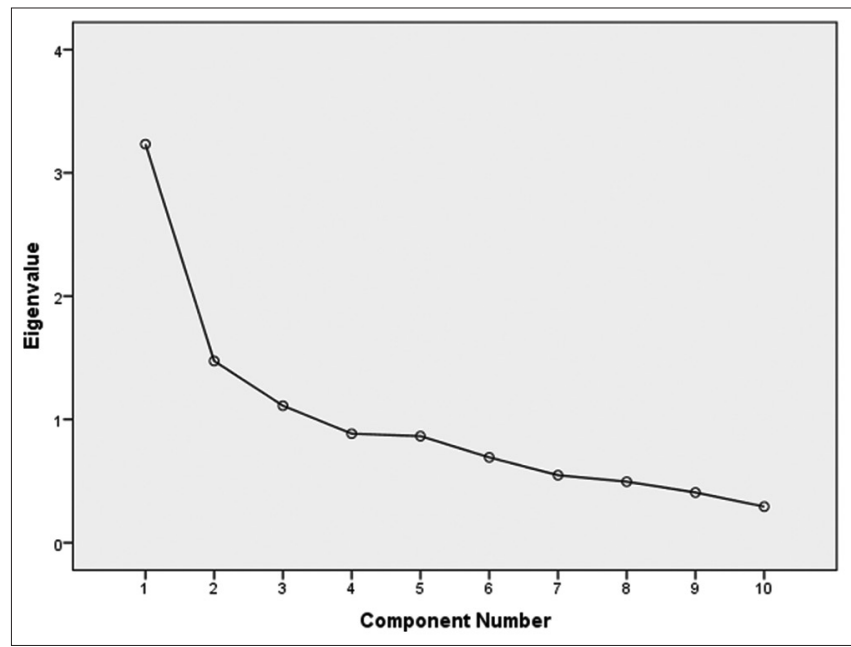

Figure 2: Scree plot

Table 2: Total variances explained ( $n=110$; principal component analysis)

\begin{tabular}{|c|c|c|c|c|c|c|c|}
\hline \multirow[t]{2}{*}{ Component } & \multicolumn{3}{|c|}{ Initial eigenvalues } & \multicolumn{3}{|c|}{ Extraction sums of squared loadings } & \multirow{2}{*}{$\begin{array}{c}\text { Rotation sums of } \\
\text { squared loadings } \\
\text { Total }\end{array}$} \\
\hline & Total & $\begin{array}{l}\text { Percentage } \\
\text { of variance }\end{array}$ & Cumulative (\%) & Total & $\begin{array}{l}\text { Percentage } \\
\text { of variance }\end{array}$ & Cumulative (\%) & \\
\hline 1 & 3.233 & 32.330 & 32.330 & 3.233 & 32.330 & 32.330 & 2.719 \\
\hline 2 & 1.474 & 14.738 & 47.068 & 1.474 & 14.738 & 47.068 & 1.964 \\
\hline 3 & 1.111 & 11.112 & 58.180 & 1.111 & 11.112 & 58.180 & 2.162 \\
\hline 4 & 0.884 & 8.841 & 67.021 & & & & \\
\hline 5 & 0.864 & 8.641 & 75.663 & & & & \\
\hline 6 & 0.692 & 6.917 & 82.579 & & & & \\
\hline 7 & 0.548 & 5.475 & 88.055 & & & & \\
\hline 8 & 0.495 & 4.947 & 93.001 & & & & \\
\hline 9 & 0.407 & 4.071 & 97.072 & & & & \\
\hline 10 & 0.293 & 2.928 & 100.000 & & & & \\
\hline
\end{tabular}


singularity. Determinant of the correlation matrix was 0.090 . Thus, multicolinearity was not a problem for the dataset. All the items correlated well and none of the correlation coefficients were predominantly large, thus contradicting elimination of any item at this stage. The rotated (promax) component matrix was a matrix of factor loadings for each variable onto each factor. The absolute values $<0.3$ were suppressed, ensuring that factor loadings within \pm 0.3 were not displayed in the output. After conducting factor rotation, those items were eliminated that loaded onto the same factor. Three subcomponents of the main construct were identified and named as below [Table 3]:

1. Items 2, 7, 9, 1, and 3: "Symptom severity" (SS)

2. Items 6, 5, and 10: "Health and social life" (HSL)

3. Items 4 and 8: "Depression and limitation of activities" (DLA).

\section{Internal consistency}

The Cronbach's alpha value for the overall CCQ-B was 0.746 and $\alpha$ for the three subscales were $0.679,0.548$, and 0.541 , respectively, indicating acceptable to good reliability [Table 4].

\section{Correlation statistics}

The correlations between the overall and CCQ-B subscales were identified to be higher than correlations between subscales [Table 5].

\section{Test-retest reliability}

CCQ-B subscale scores were largely stable with insignificant mean differences, thus indicating acceptable test-retest reliability [Table 6].

\section{Concurrent validity}

CCQ-B total score had a significantly strong correlation with CAT (CCQ-B: $32.3 \pm 8.3$ vs. CAT: $25.6 \pm 6.4$, Pearson's $r=0.699, P<0.001)$ scores, thus ensuring acceptable concurrent validity.

\section{Confirmatory factor analysis}

The indices of CFA that confirmed model fit (Chi-square $=49.843$, $\mathrm{df}=32$, probability level $=0.023$ ) were as follows: $\mathrm{CFI}=0.688$, $\mathrm{NFI}=0.512, \mathrm{TLI}=0.562, \mathrm{RMSEA}=0.072, \mathrm{SRMR}=0.275$, $\mathrm{BIC}=157.954$, and Hoelter index $($ at $\alpha 0.05)=102$, indicating a mediocre model fit and three distinct components [Figure 3].

\section{Discussion}

The English version of the CCQ is an already validated questionnaire comprised of 10 questions, framed within 3 components, and assessing SS and QoL in patients with COPD; however, until now, no validated Bengali version of the questionnaire was available. The English questionnaire underwent standardized forward-backward translation to produce the CCQ-B. In similarity with the original three subscales of English version, EFA using PCA of the CCQ-B identified three components but different from the original version, while the overall model goodness-of-fit was further confirmed by CFA. Thus, CCQ-B was valid and reliable

\begin{tabular}{|c|c|c|c|}
\hline \multirow{2}{*}{ Items } & \multicolumn{3}{|c|}{ Components } \\
\hline & 1 (SS) & 2 (HSI) & 3 (DLA) \\
\hline 2 & 0.965 & & \\
\hline 7 & 0.824 & & \\
\hline 9 & 0.382 & & \\
\hline 1 & 0.362 & & \\
\hline 6 & & 0.732 & \\
\hline 5 & & 0.617 & \\
\hline 10 & & 0.593 & \\
\hline 3 & 0.469 & & \\
\hline 4 & & & 0.950 \\
\hline 8 & & & 0.596 \\
\hline
\end{tabular}

\begin{tabular}{|c|c|c|}
\hline & $\begin{array}{l}\text { Cronbach's } \\
\text { alpha }\end{array}$ & $\begin{array}{l}\text { ICC coefficient } \\
(95 \% \mathrm{Cl})\end{array}$ \\
\hline Overall CCQ-B & 0.746 & $0.746(0.668-0.811)$ \\
\hline \multicolumn{3}{|l|}{ CCQ-B components } \\
\hline Symptom severity & 0.679 & $0.679(0.574-0.765)$ \\
\hline Health and social life & 0.548 & $0.548(0.379-0.677)$ \\
\hline Depression and & 0.541 & $0.541(0.330-0.685)$ \\
\hline
\end{tabular}

ICC: Intraclass correlation coefficient, CI: Confidence interval, CCQ: Clinical COPD questionnaire, COPD: Chronic obstructive pulmonary disease

\begin{tabular}{|c|c|c|c|c|}
\hline & SS & HSL & DLA & Overall score \\
\hline SS & 1.000 & 0.328 & 0.458 & 0.868 \\
\hline HSL & 0.328 & 1.000 & 0.309 & 0.682 \\
\hline DLA & 0.458 & 0.309 & 1.000 & 0.698 \\
\hline Overall score & 0.868 & 0.682 & 0.698 & 1.000 \\
\hline
\end{tabular}

Determinant $=0.000$. SS: Symptom severity, HSL: Health and social life, DLA: Depression and limitation of activities

with Cronbach's $\alpha$, ICC, concurrent validity, and test-retest reliability within acceptable limits.

One of the major strengths of this study was to apply EFA and CFA on two different samples as recommended. ${ }^{[17-19]}$ Our study shows that the overall and individual subscales of CCQ-B were similar to other studies. Unlike other validation studies, there was no control (normal/healthy) group; hence, assessment of item discriminant validity was 
Banerjee, et al.: Validation of Bengali clinical COPD questionnaire

Table 6: Test-retest reliability analysis of the clinical chronic obstructive pulmonary disease questionnaire-Bengali version questionnaire $(n=30)$

\begin{tabular}{|c|c|c|c|c|c|}
\hline \multirow[t]{2}{*}{ Components } & \multicolumn{2}{|c|}{ Mean (SD) } & \multirow[t]{2}{*}{ Pearson's $r$} & \multirow{2}{*}{$\begin{array}{l}\text { Score difference } \\
\text { Mean }(95 \% \mathrm{CI})\end{array}$} & \multirow[t]{2}{*}{$P^{*}$} \\
\hline & Test score & Retest score & & & \\
\hline SS & $17.2(5.1)$ & $17.3(5.0)$ & 0.999 & $-0.053(-0.153-0.047)$ & 0.284 \\
\hline HSL & $8.4(3.6)$ & $8.4(3.7)$ & 0.996 & $-0.040(-0.160-0.080)$ & 0.501 \\
\hline DLA & $6.5(2.7)$ & $6.5(2.6)$ & 0.993 & $0.033(-0.086-0.153)$ & 0.573 \\
\hline Overall score & $32.1(7.7)$ & $32.1(7.5)$ & 0.998 & $-0.060(-0.257-0.137)$ & 0.539 \\
\hline
\end{tabular}

*Paired $t$-test. SD: Standard deviation, CI: Confidence interval, SS: Symptom severity, HSL: Health and social life, DLA: Depression and limitation of activities

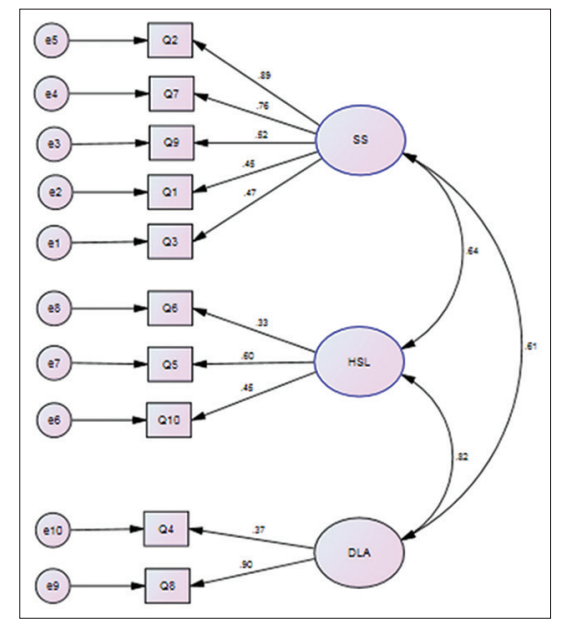

Figure 3: The confirmatory factor analysis model; SS: Symptom severity, HSL: Health and social life, DLA: Depression and limitation of activities

not possible. Besides, responsiveness of the questionnaire was not assessed because the treatment offered by the study site was homeopathy exclusively and that was not an accepted standard treatment for COPD. Our findings revealed that the internal consistency was overall reasonable and comparable to the existing versions. However, the individual Health and Social Life (HSL) and DLA components showed a fairly low Cronbach's alpha. This fact was also reflected on the lower correlation between subscales shown in Table 5. Alpha measure depends on the number of items and covariances between items. A score $<0.70$ suggests that the items within the tool may not be measuring the same underlying construct and poorly correlated items need to be deleted. However, as the number of items was not too many, correlation coefficients with the "social activities" and overall score were higher than 0.30 , and retaining all the items revealed a fair fit in the CFA model, we decided not to eliminate any items. It should also be kept in mind that alpha has very strict assumptions including unidimensionality, uncorrelated errors, and identical covariances between the items (tau equivalence). In most of the cases, these assumptions are violated and thus over- or under-estimate the true reliability. Thus, alpha may not be the best choice for measuring reliability. The probable alternative may be Guttman's lambda or McDonald's omega which are not based on tau-equivalence. ${ }^{[20]}$ There were satisfactorily high interitem correlations among the subscales. While running PCA, sample size achieved by us was similar to the original CCQ development and validation study and other translations, but we achieved more 120 samples to perform CFA. Fifty percent $(5 / 10)$ of the items had strong factor loadings of 0.60 and above. ${ }^{[21]}$ Second, the CCQ-B was administered to the patients who were competent in reading and understanding the Bengali language. Therefore, the study findings are generalized to Bengali population only. Finally, the three-component model had an acceptable model fit in CFA. Thus, further translation and validation of the questionnaire aew warranted into other Indian languages and on larger sample for better and large-scale utilization in a multi-ethnic Indian population. Another drawback was the consecutive sampling used that might have introduced sampling bias into the study.

Thus, the validated CCQ-B served as an important patient-administered outcome questionnaire to measure the $\mathrm{SS}$ and QoL in patients suffering from COPD. Future research should include utilization of the CCQ-B as outcome measure in clinical trials. Hence, the responsiveness and sensitivity to change of the CCQ-B to measure symptoms and treatment effects need to be determined in future investigations. Finally, to confirm that CCQ-B can measure the impact of clinical treatment, the final step in this development will be to define a minimally important difference of change reflecting a clinically meaningful difference.

\section{ConcLusion}

The developed CCQ-B contains 10 items which are constructed within three-component model. It is a reasonably valid and reliable tool, enabled to measure the QoL in Bengali patients suffering from COPD. However, to strengthen the validity of the CCQ-B, further analyses are recommended.

\section{Acknowledgments}

We would like to acknowledge the institutional heads for allowing us to conduct the study. We are also grateful to the patients for their participation.

\section{Financial support and sponsorship}

Nil.

\section{Conflicts of interest}

There are no conflicts of interest. 


\section{RefERENCES}

1. Vestbo J, Hurd SS, Agustí AG, Jones PW, Vogelmeier C, Anzueto A, et al. Global strategy for the diagnosis, management, and prevention of chronic obstructive pulmonary disease: GOLD executive summary. Am J Respir Crit Care Med 2013;187:347-65.

2. van der Molen T, Willemse BW, Schokker S, ten Hacken NH, Postma DS, Juniper EF. Development, validity and responsiveness of the clinical COPD Questionnaire. Health Qual Life Outcomes 2003;1:13.

3. Ringbaek T, Martinez G, Lange P. A comparison of the assessment of quality of life with CAT, CCQ, and SGRQ in COPD patients participating in pulmonary rehabilitation. COPD 2012;9:12-5.

4. Tsiligianni IG, van der Molen T, Moraitaki D, Lopez I, Kocks JW, Karagiannis $\mathrm{K}$, et al. Assessing health status in COPD. A head-to-head comparison between the COPD assessment test (CAT) and the clinical COPD questionnaire (CCQ). BMC Pulm Med 2012;12:20.

5. Dodd JW, Hogg L, Nolan J, Jefford H, Grant A, Lord VM, et al. The COPD assessment test (CAT): Response to pulmonary rehabilitation. A multicentre, prospective study. Thorax 2011;66:425-9.

6. Cave AJ, Atkinson L, Tsiligianni IG, Kaplan AG. Assessment of COPD wellness tools for use in primary care: An IPCRG initiative. Int J Chron Obstruct Pulmon Dis 2012;7:447-56.

7. Global Initiative for Chronic Obstructive Lung Disease. Pocket Guide to COPD Diagnosis, Management, and Prevention. Guide for Health Care Professionals. 2017 th ed.. Global Initiative for Chronic Obstructive Lung Disease, Inc.; 2017. Available from: http://www.goldcopd.org. [Last accessed on 2017 May 11].

8. Preacher KJ, MacCallum RC. Exploratory factor analysis in behavior genetics research: Factor recovery with small sample sizes. Behav Genet 2002;32:153-61.

9. Gorsuch RL. Factor Analysis. $2^{\text {nd }}$ ed.. Hillsdale: Lawrence Erlbaum Associates; 1983.

10. Sitzia J. How valid and reliable are patient satisfaction data? An analysis of 195 studies. Int J Qual Health Care 1999;11:319-28.

11. Streiner DL, Norman GR. Health Measurement Scales: A Practical Guide to Their Development and Use. Oxford: Oxford University Press; 2008.

12. Cicchetti DV. Guidelines, criteria, and rules of thumb for evaluating normed and standardized assessment instruments in psychology. Psychol Assess 1994;6:284-90.

13. Maccallum RC, Browne MW, Sugawara HM. Power analysis and determination of sample size for covariance structure modeling of fit involving a particular measure of model. Psychol Methods 1996;13:130-49.

14. Cohen J. Statistical Power Analysis for the Behavorial Sciences. $2^{\text {nd }}$ ed Hillsdale, NJ: Lawrence Erlbaum Associates; 1977.

15. Hu L, Bentler P. Cutoff criteria for fit indexes in covariance structure analysis: Conventional criteria versus new alternatives. Struct Equ Modeling 1999;6:1-55.

16. Brown TA. Confirmatory Factor Analysis for Applied Research. New York: Guilford Press; 2006.

17. Costello A, Osborne J. Best practices in exploratory factor analysis: Four recommendations for getting the most from your analysis. Pract Assess Res Eval 2005;10:1-9. Available from: https://pareonline.net/ pdf/v10n7.pdf. [Last accessed on 2018 Dec 12].

18. Henson R, Roberts J. Use of exploratory factor analysis in published research: Common errors and some comment on improved practice. Educ Psychol Meas 2006;66:393-416.

19. Worthington R, Whittaker T. Scale development research: A content analysis and recommendations for best practices. Couns Psychol 2006;34:806-38.

20. Dunn TJ, Baguley T, Brunsden V. From alpha to omega: A practical solution to the pervasive problem of internal consistency estimation. $\mathrm{Br}$ J Psychol 2014;105:399-412.

21. Garson D. Statnotes: Topics in Multivariate Analysis: Factor Analysis. Available from: http://faculty.chass.ncsu.edu/garson/pa765/statnote. htm. [Last accessed on 2018 Dec 07]. 